\title{
Impact of precipitation seasonality changes on isotopic signals in polar ice cores: a multi-model analysis
}

\author{
G. Krinner ${ }^{\mathrm{a}, *}$, M. Werner ${ }^{\mathrm{b}}$ \\ a Laboratoire de Glaciologie et de Géophysique de l'Environnement, CNRS-UJF, Grenoble, France \\ b Max-Planck-Institut für Biogeochemie, Jena, Germany
}

Received 4 April 2003; received in revised form 20 August 2003; accepted 19 September 2003

\begin{abstract}
For Central Greenland, water isotope analysis indicates a temperature difference of about $10^{\circ} \mathrm{C}$ since the Last Glacial Maximum (LGM). However, borehole thermometry and gas diffusion thermometry indicate that LGM surface temperatures were about $20^{\circ} \mathrm{C}$ colder than today. Two general circulation model studies have shown that changes in the seasonal precipitation timing in Central Greenland might have caused a warm bias in the LGM water isotope proxy temperatures, and that this bias could explain the difference in the estimated paleotemperatures. Here we present an analysis of a number of atmospheric general circulation model simulations mostly done within the framework of the Paleoclimate Modeling Intercomparison Project. The models suggest that the seasonal cycle of precipitation and surface mass balance over Central Greenland at the LGM might have been very different from today. This supports the idea that the accuracy of the water isotope thermometry at the LGM in Greenland might be compromised as a result of a modified surface mass balance seasonality. However, the models disagree on the amplitude and sign of the bias. For Central East Antarctica, a strong seasonality effect on the LGM isotopic signal is not simulated by any of the analyzed models. For the mid-Holocene (6 kyr BP) the models suggest relatively weak isotope paleothermometry biases linked to changes in the surface mass balance seasonality over both ice sheets.

(C) 2003 Elsevier B.V. All rights reserved.
\end{abstract}

Keywords: ice cores; paleothermometry; water isotopes; general circulation model

\section{Introduction}

The observation of very high regional correlations between the annual mean isotopic composition of surface snow and annual temperatures, both over Greenland [1] and Antarctica [2], has

\footnotetext{
* Corresponding author. Present address: LGGE, DU BP 96, 38402 St Martin d'Hères Cedex, France. Tel.: +33-4-76-82-42-36.

E-mail address: krinner@ujf-grenoble.fr (G. Krinner).
}

led to the use of these correlations for the reconstruction of paleotemperatures from polar ice cores. The basic assumption in this approach is that the linear relationship between surface temperature $T_{\mathrm{s}}$ and isotopic composition $\delta$ (essentially a normalized ratio between heavy and light water isotope content) did not change over time. In other words, one supposes that the relationship between $\delta$ and $T_{\mathrm{s}}$ at a given place over time ('the temporal slope') is identical or very close to the observed present slope over the nearby region ('the modern spatial slope'). However, growing 
evidence exists that 'temporal slopes' and 'spatial slopes' might not always be identical [3-5]. For Summit, Central Greenland, the inversion of GRIP borehole temperatures [6,7] and independent temperature estimates by gas diffusion measurements [8] have led to the conclusion that for the Last Glacial Maximum (LGM), water isotope paleothermometry seems to be affected by a warm bias of about $10^{\circ} \mathrm{C}$. In a similar way, the validity of the LGM isotope thermometry for the Vostok core in Central East Antarctica has been challenged [9]. However, it has been shown [10] that borehole temperature inversion at Vostok yields unreliable results for the LGM because the low accumulation rate at the Vostok drilling site induces a too strong smoothing of the temperature signal within the ice.

Several mechanisms might have changed the $\delta / T_{\mathrm{s}}$ relationship in the past [3]. Broadly, one can divide the various influences on the isotopic composition of ice sheet surface snow into two groups: a remote and a local part of the isotopic signal. The remote part of the isotopic signal concerns all the processes that influence the isotopic composition before the precipitation forms over the ice sheet itself, while the local part concerns the processes taking place at the precipitation site.

As an example for a remote impact on the isotopic composition of ice sheet surface snow, it was demonstrated [11] that an assumed glacial cooling of 'tropical' ocean temperatures by $5^{\circ} \mathrm{C}$ would lead to a temporal $\delta / T_{\mathrm{s}}$ slope close to that derived from borehole paleothermometry in Greenland.

A well-known example of local mechanisms possibly affecting the $\delta$ signal is the strong short-term covariance between temperature and precipitation over ice sheets $[1,12,13]$ : Days with high precipitation rates tend to be warmer than the mean of the corresponding month. This implies that the precipitation-dependent $\delta$ signal records anomalous warm atmospheric conditions. However, long-term $\delta$ variations will not automatically be biased by this effect as the shortterm temperature/precipitation covariance might have been stable in time.

As another local effect, it was proposed [14] that changes in seasonality could have a large effect on the isotopic thermometer. If, for exam- ple, at constant annual mean temperature, the relative weight of summer precipitation in the accumulated snow (compared to the annual total) increases, then the isotopic composition of the resulting mean snow will be biased towards lighter (= 'warmer') isotope values. Thus, annual mean isotope values do not actually reflect annual mean temperatures, but annual precipitationweighted temperatures:

$T_{\mathrm{B}}=\frac{\sum\left(T_{m} P_{m}\right)}{\sum P_{m}}$

with $m$ precipitation events occurring over the year, $P_{m}$ the precipitation amounts of the individual events, and $T_{m}$ the corresponding surface temperatures during the precipitation events (if only the seasonal cycle is to be analyzed, $P_{m}$ and $T_{m}$ are monthly mean values). If re-evaporation $E_{m}$ of surface snow is substantial, the isotopic composition reflects more closely temperatures weighted by surface mass balance $\mathrm{SMB}_{m}$ (here defined as $\left.\mathrm{SMB}_{m}=P_{m}-E_{m}\right)^{1}$, and not by precipitation $P_{m}$ only. Several general circulation model (GCM) studies [15-17] showed that changes in precipitation seasonality might indeed be responsible for a large part of the $10^{\circ} \mathrm{C}$ warm bias in the Greenland LGM water isotope paleothermometry. These GCM studies suggest no major changes to the water isotope/temperature relationship for Antarctica. This is also shown by a study using the GISS isotopic GCM [18], which suggests that neither changes in precipitation seasonality nor in its origin adversely affect the validity of the LGM isotopic paleothermometer in Central Antarctica.

In the framework of the Paleoclimate Modeling Intercomparison Project (PMIP) [19], more than 20 climate models $^{2}$ (mostly GCMs) have been run with identical boundary conditions for the midHolocene (6 kyr BP) and the LGM. It was not the objective of PMIP to address the question of

\footnotetext{
1 Melting of surface snow is neglected for the calculation of SMB, since it never occurs in Central East Antarctica, and only very rarely in Central Greenland: Data from the Kenton automatic weather station near the Greenland Summit (http:// uwamrc.ssec.wisc.edu/aws/awsproj.html) show that, in more than 7 years of record, hourly surface air temperatures exceeded $0^{\circ} \mathrm{C}$ on only 12 occasions.
} 
the validity of water isotope thermometry. None of the existing isotopic GCMs, such as the ECHAM GCM [16], the GISS GCM [18] and the recently developed isotopic version of the Melbourne University GCM [5], participated in PMIP and many diagnostics of interest for water isotope studies (e.g. surface inversion strengths or atmospheric moisture fluxes) from the participating models were not saved in the PMIP archives. However, the simulated monthly values of precipitation $P_{m}$, evaporation $E_{m}$ and temperature $T_{m}$ are available for most of the PMIP simulations. In the following, these simulations are analyzed with respect to the seasonal cycles of SMB over the central regions of the two existing ice sheets. In addition to the PMIP models, output was analyzed from three sets of GCM simulations that were not carried out within the PMIP framework. The first is the set of simulations carried out with the ECHAM4 isotopic GCM [16,17]. The second set uses the LMDZ GCM version 2 [15]. We furthermore added a set of simulations carried out with the more recent version 3 of LMDZ.

\footnotetext{
2 Names of the models used in this study are as follows: BMRC, Bureau of Meteorology Research Center, Melbourne; CCC, Canadian Climate Center, Toronto; CCM1 and CCM3, National Center for Atmospheric Research (NCAR) community climate model; CCSR, Center for Climate System Research, Tokyo; CNRM, Centre National de Recherche Météorologique, Toulouse; CSIRO, Commonwealth Scientific and Industrial Research Organisation, Melbourne; ECHAM, European Center/Hamburg, Max-Planck-Institut für Meteorologie, Hamburg; GENESIS, NCAR Global Environmental and Ecological Simulation of Interactive Systems; GFDL, Geophysical Fluid Dynamics Laboratory; GISS, Goddard Institute for Space Studies, NASA, New York; LMCELMD, Laboratoire de Météorologie Dynamique, Paris; MRI, Meteorological Research Institute, Tokyo; UGAMP, U.K. Universities Global Atmospheric Modeling Programme; UIUC, University of Illinois at Urbana-Campaign; UKMO, U.K. Meteorological Office; YONU, Yonsei University, Seoul. 'cal' stands for calculated sea surface temperatures (using a slab ocean); 'fix', for prescribed sea surface temperatures. For a description of the models, the design of the numerical experiments, and access to the PMIP database, see http:// www-lsce.cea.fr/pmip/. Several simulations used here were not done within the PMIP framework: ECHAM4, European Center/Hamburg, Max-Planck-Institut für Meteorologie, Hamburg [16]; LMDZ2, Laboratoire de Météorolgie Dynamique, Paris [15]; LMDZ3, a more recent version of the LMDZ GCM.
}

The central question addressed in this study is whether a larger number of climate models support previous findings [15-18] that LGM isotope paleothermometry may be influenced by changes in SMB seasonality in Central Greenland, but not in Antarctica. Furthermore simulations of the mid-Holocene climate (6 kyr BP) are analyzed to determine whether for this period water isotope paleothermometry may be adversely affected by SMB seasonality changes, too.

\section{The analytical approach}

To analyze the GCM model results, we apply a two-step analytical approach. First, we quantify the models' capability of simulating the presentday climate near Summit (Central Greenland) and Vostok (East Antarctica) in agreement with available observations. Then, LGM and mid-Holocene simulations are analyzed for the models with satisfying present-day skill. The evaluation of the paleosimulations focuses on simulated seasonal changes of SMB and/or temperature during the past. The aim is to quantify the impact of past seasonal changes of precipitation on the mean temperature estimates derived from $\delta$ values measured in polar ice cores.

\subsection{Definition of model skill}

We restrict our analysis of model skills to temperature and SMB, because these are the basic variables used for the assessment of the impact of precipitation seasonality on isotopic signals in the following sections. Observed monthly mean temperatures at Vostok and Summit are trustworthy, but observations of monthly amounts of SMB in polar regions are notoriously unreliable [20]. Therefore, the analysis of model skill uses monthly mean values of surface air temperature, but only annual mean SMB. Model skill $S$ is defined such that $S \in[0 ; 1]$, with $S=0$ indicating poor model performance, and $S=1$, excellent model-data agreement. We calculate model skill $S$ as the geometric mean of temperature skill $S_{\mathrm{T}}$ and SMB skill $S_{\mathrm{B}}$ over the Vostok and Summit regions: 
$S=\left(S_{\mathrm{B}, \text { Summit }} S_{\mathrm{T}, \text { Summit }} S_{\mathrm{B}, \text { Vostok }} S_{\mathrm{T}, \text { Vostok }}\right)^{1 / 4}$

The use of a geometric mean instead of an arithmetic mean in the definition of $S$ favors models that perform reasonably well in all four aspects, while it penalizes models that perform exceptionally well (or badly) in one particular aspect only.

The definition of temperature skill $S_{\mathrm{T}}$ uses the annual mean of the absolute monthly surface air temperature bias:

$E_{\mathrm{T}}=\frac{1}{365} \sum_{i=1}^{12} n_{i}\left|T_{\mathrm{sim}, i}-T_{\mathrm{obs}, i}\right|$

where $n_{i}$ is the number of days in each of the 12 months and $T_{\mathrm{sim}, i}\left(T_{\mathrm{obs}, i}\right)$ denotes the simulated (observed) monthly surface air temperature. The temperature skill is then defined as:

$S_{\mathrm{T}}=\exp \left(-E_{\mathrm{T}} / E_{\mathrm{T}, 0}\right)$

with $E_{\mathrm{T}, 0}=10 \mathrm{~K}$. This is a convenient, albeit somewhat arbitrary way to assess the models' capacity of reproducing the observed temperatures. If the modeled monthly temperatures perfectly match the observations for all months, then $S_{\mathrm{T}}$ will be equal to 1 . Conversely, for models that simulate temperature very badly, $S_{\mathrm{T}}$ will be close to zero.

SMB skill $S_{\mathrm{B}}$ is simply defined as:

$S_{\mathrm{B}}=\min \left(\frac{\mathrm{SMB}_{\text {sim }}}{\mathrm{SMB}_{\text {obs }}}, \frac{\mathrm{SMB}_{\text {obs }}}{\mathrm{SMB}_{\text {sim }}}\right)$

Like the temperature skill $S_{\mathrm{T}}$, the SMB skill $S_{\mathrm{B}}$ ranges between 1 (perfect agreement) and 0 (extreme misfit).

In several tables in this paper, a mean value for all the selected models is given (declared 'model mean' in the tables). This mean value is calculated by weighting each model with its skill $S$. The associated standard deviations also take into account this weighting.

\subsection{Estimating effects of $S M B$ seasonality}

For all the selected PMIP simulations, we calculate both annual (arithmetic) mean surface temperature $T_{\mathrm{S}}$ and annual SMB-weighted surface temperature $T_{\mathrm{B}}$ for the grid box enclosing the
Summit $\left(38^{\circ} \mathrm{W}, 72^{\circ} \mathrm{N}\right)$ and the Vostok $\left(106^{\circ} \mathrm{E}\right.$, $78^{\circ} \mathrm{S}$ ) drill site, respectively. Monthly SMB is calculated as precipitation minus evaporation: $B_{m}=P_{m}-E_{m}$. If $E_{m}>P_{m}$, then $B_{m}$ is set to zero and the evaporation excess $E_{m}-P_{m}$ is subtracted from the previous month's SMB $B_{m-1}$ (if this leads to a negative $B_{m-1}, B_{m-1}$ is set to zero and the excess snow mass is subtracted from $B_{m-2}$, and so on). To estimate the impact of SMB seasonality, we essentially apply an approach based on the idea to follow as closely as possible the methodology used in ice core water isotope analysis [15]. First, the SMB-weighted surface air temperature $T_{\mathrm{B}}$, based on monthly values of surface air temperature and SMB, is calculated for each grid point of the two ice sheets. A linear spatial regression between $T_{\mathrm{B}}$ and $T_{\mathrm{s}}$ is calculated for each ice sheet and each climate model:

$T_{\mathrm{B}}=s T_{\mathrm{s}}+b$

where $s$ is the equivalent of the so-called modern spatial slope of the isotope-temperature relationship. The next step consists in calculating $T_{\mathrm{B}}$ at the deep ice drilling sites (Summit and Vostok) for the past periods ( 6 and $21 \mathrm{kyr}$ BP) in each of the models. This step is equivalent to measuring mean mid-Holocene and LGM $\delta$ values in the ice cores. Because the spatial variability of seasonal cycles of precipitation in GCMs over the polar ice sheets is usually very high [21], we chose to represent Summit and Vostok by relatively large areas around the actual drill sites (maximum distance about $400 \mathrm{~km}$ ), rather than by the nearest model grid point. For Summit, all grid points with longitudes between $45^{\circ} \mathrm{W}$ and $38^{\circ} \mathrm{W}$ and latitudes between $69^{\circ} \mathrm{N}$ and $76^{\circ} \mathrm{N}$ are taken into account. For Vostok, the corresponding limits are $90^{\circ} \mathrm{E}$, $120^{\circ} \mathrm{E}, 74^{\circ} \mathrm{S}$, and $82^{\circ} \mathrm{S}$. Inverting Eq. 6 allows to calculate an estimated surface air temperature $\tilde{T}_{\mathrm{s}}$ from the modeled $T_{\mathrm{B}}$ :

$\tilde{T}_{\mathrm{s}}=\frac{1}{s}\left(T_{\mathrm{B}}-b\right)$

The estimated surface air temperature $T_{\mathrm{s}}$ is then compared to the actually simulated surface air temperature $T_{\mathrm{s}}$, yielding a bias:

$\beta=\tilde{T}_{\mathrm{s}}-T_{\mathrm{s}}$ 
Given present-day simulated $T_{\mathrm{B}}$ and $T_{\mathrm{s}}$, the bias $\beta$ allows to evaluate the applicability of the relationship between $T_{\mathrm{B}}$ and $T_{\mathrm{s}}$ at the drill site, that is, essentially the quality of the relationship between $T_{\mathrm{B}}$ and $T_{\mathrm{s}}$. In the following, the bias will be noted $\beta_{0}$ when Eq. 8 is applied to present-day model output.

In ice core isotopic studies, past temperature changes are estimated through:

$\Delta \tilde{T}_{\mathrm{s}}=\frac{1}{s} \Delta \delta$

where $\Delta \delta$ is the measured temporal change of isotopic composition, and $s$ the experimentally derived slope of the spatial relationship between

Table 1

Temperature error $E_{\mathrm{T}}$, ratio between simulated and observed annual SMB (dimensionless), and total model skill $S$ (dimensionless) for the present-day climate in the Vostok (AA) and Summit (GL) areas (see Eqs. 2 and 3) for the different GCM simulations (fix: prescribed sea surface temperatures; cal: simulated slab ocean sea surface temperatures)

\begin{tabular}{|c|c|c|c|c|c|}
\hline & \multicolumn{2}{|c|}{$E_{\mathrm{T}}\left({ }^{\circ} \mathrm{C}\right)$} & \multicolumn{2}{|c|}{$\mathrm{SMB}_{\text {sim }} / \mathrm{SMB}_{\text {obs }}$} & \multirow[t]{2}{*}{$S$} \\
\hline & $\mathrm{AA}$ & GL & $\mathrm{AA}$ & GL & \\
\hline UKMO fix & 2.6 & 2.0 & 1.13 & 1.04 & 0.85 \\
\hline ECHAM4 fix & 2.7 & 2.6 & 0.86 & 1.05 & 0.83 \\
\hline UKMO cal & 2.3 & 2.0 & 1.21 & 1.15 & 0.83 \\
\hline LMDZ3 fix & 3.4 & 1.7 & 1.28 & 1.18 & 0.79 \\
\hline UIUC11 fix & 5.6 & 7.8 & 1.26 & 1.00 & 0.67 \\
\hline GENESIS2 cal & 9.0 & 4.6 & 0.94 & 1.20 & 0.67 \\
\hline ECHAM3 fix & 4.7 & 2.0 & 2.46 & 0.87 & 0.65 \\
\hline GENESIS2 fix & 7.9 & 4.9 & 0.76 & 1.26 & 0.64 \\
\hline CCM3 fix & 1.1 & 7.9 & 0.47 & 0.85 & 0.63 \\
\hline LMDZ2 fix & 7.1 & 5.1 & 0.72 & 1.38 & 0.63 \\
\hline YONU fix & 6.2 & 8.8 & 0.66 & 0.99 & 0.62 \\
\hline UGAMP cal & 3.0 & 3.2 & 2.45 & 0.64 & 0.61 \\
\hline UGAMP fix & 4.1 & 3.3 & 2.34 & 0.62 & 0.60 \\
\hline GENESIS $1 \mathrm{cal}$ & 8.4 & 11.4 & 1.26 & 0.83 & 0.55 \\
\hline CSIRO fix & 16.4 & 9.7 & 0.98 & 1.00 & 0.52 \\
\hline GISS-IIP fix & 2.3 & 3.2 & 0.32 & 0.38 & 0.51 \\
\hline MRI2 cal & 11.7 & 11.2 & 1.74 & 0.73 & 0.45 \\
\hline GFDL cal & 9.3 & 11.0 & 3.68 & 1.08 & 0.43 \\
\hline GFDL fix & 9.9 & 11.3 & 3.79 & 1.02 & 0.42 \\
\hline $\mathrm{CCC} 2.0 \mathrm{fix}$ & 3.1 & 2.4 & 19.15 & 2.00 & 0.35 \\
\hline MRI2 fix & 18.3 & 14.6 & 2.88 & 1.13 & 0.33 \\
\hline CCC2.0 cal & 5.5 & 3.2 & 20.84 & 2.08 & 0.31 \\
\hline BMRC fix & 8.5 & 8.0 & 22.73 & 0.93 & 0.30 \\
\hline CNRM-2 fix & 7.7 & 17.4 & 0.17 & 2.38 & 0.28 \\
\hline CCSR1 fix & 8.7 & 12.5 & 11.56 & 3.01 & 0.24 \\
\hline CCM1 cal & 21.0 & 6.4 & 17.15 & 1.57 & 0.22 \\
\hline LMCELMD5 fix & 25.4 & 16.9 & 6.21 & 6.99 & 0.14 \\
\hline LMCELMD4 fix & 24.7 & 29.5 & 6.84 & 0.00 & 0.00 \\
\hline
\end{tabular}

present surface air temperature and surface snow isotopic composition. This is equivalent to:

$\Delta \tilde{T}_{\mathrm{s}}=\frac{1}{S} \Delta T_{\mathrm{B}}$

in this study. The equivalent of the bias of isotope-derived temperature changes caused by variations in SMB seasonality is then the difference between $\Delta \tilde{T}_{\mathrm{s}}$ and actually simulated surface air temperature change $\Delta T_{\mathrm{s}}$ :

$\Delta \beta=\Delta \tilde{T}_{\mathrm{s}}-\Delta T_{\mathrm{s}}=\frac{1}{S} \Delta T_{\mathrm{B}}-\Delta T_{\mathrm{s}}$

That is, $\Delta \beta$ yields an estimate of the error induced by applying the present-day spatial slope to calculate temporal changes of $T_{\mathrm{s}}$. If the temporal and spatial relations between $T_{\mathrm{s}}$ and $T_{\mathrm{B}}$ are identical, then $\Delta \beta$ is zero.

\section{Results}

In this section, the simulated present-day climate of the different GCMs is first evaluated and the model skill is calculated. The method described above is then applied to the present-day simulations of the selected models in order to evaluate the associated errors. Afterwards, the method is applied to the paleoclimate model outputs to evaluate the possible isotope paleothermometry biases linked to SMB seasonality changes.

\subsection{Present}

\subsubsection{Simulated present climate: model skill}

Table 1 gives an overview of temperature error $E_{\mathrm{T}}$, ratio $\mathrm{SMB}_{\text {sim }} / \mathrm{SMB}_{\text {obs }}$ and calculated skills of the different models in the vicinity of the Summit and Vostok drilling sites. The models are listed in order of decreasing skill. For Summit, we used temperature data from the Kenton automatic weather station ${ }^{3}$ near Summit for the years 1987 1995 and annual mean accumulation derived from high-resolution isotope profiles [22]. For Vostok,

\footnotetext{
${ }^{3}$ http://uwamrc.ssec.wisc.edu/aws/awsproj.html.
} 
Table 2

Present-day bias $\beta_{0}$ of the derived surface temperature (Eq. 8), slope $s$ (Eq. 6) of the relationship between surface air temperature $T_{\mathrm{s}}$ and SMB-weighted surface air temperature $T_{\mathrm{B}}$, and $r^{2}$ of the continental-scale correlation between $T_{\mathrm{s}}$ and $T_{\mathrm{B}}$ for the areas around Summit and Vostok

\begin{tabular}{|c|c|c|c|c|c|c|}
\hline & \multicolumn{3}{|c|}{ Vostok (Antarctica) } & \multicolumn{3}{|c|}{ Summit (Greenland) } \\
\hline & $\begin{array}{l}\beta_{0} \\
\left({ }^{\circ} \mathrm{C}\right)\end{array}$ & $s$ & $r^{2}$ & $\begin{array}{l}\beta_{0} \\
\left({ }^{\circ} \mathrm{C}\right)\end{array}$ & $s$ & $r^{2}$ \\
\hline UKMO fix & -1.3 & 0.91 & 0.96 & -0.4 & 1.03 & 0.93 \\
\hline ECHAM4 fix & -0.8 & 0.92 & 0.99 & -2.0 & 0.88 & 0.91 \\
\hline UKMO cal & -0.3 & 0.87 & 0.97 & -0.6 & 0.94 & 0.92 \\
\hline LMDZ3 fix & -0.1 & 0.98 & 0.99 & -0.1 & 0.92 & 0.71 \\
\hline UIUC11 fix & 2.7 & 0.96 & 0.94 & -1.7 & 1.04 & 0.80 \\
\hline GENESIS2 cal & -1.2 & 0.92 & 0.99 & -1.6 & 0.93 & 0.94 \\
\hline ECHAM3 fix & -0.3 & 0.99 & 0.97 & -0.4 & 0.89 & 0.96 \\
\hline GENESIS2 fix & -1.3 & 0.92 & 0.99 & -2.2 & 0.94 & 0.87 \\
\hline CCM3 fix & 1.7 & 0.86 & 0.97 & -0.4 & 0.99 & 0.78 \\
\hline LMDZ2 fix & -0.1 & 0.92 & 0.98 & -0.2 & 0.85 & 0.85 \\
\hline YONU fix & 0.0 & 1.09 & 0.91 & -5.1 & 0.74 & 0.54 \\
\hline UGAMP cal & -0.2 & 1.07 & 0.94 & 0.7 & 0.58 & 0.62 \\
\hline UGAMP fix & -0.6 & 1.05 & 0.91 & 1.8 & 0.53 & 0.43 \\
\hline Model mean & $-0.2 \pm 1.1$ & & & -0.9 & & \\
\hline
\end{tabular}

we used temperatures and SMB measured at the manned station [23]. As can be seen in Table 1, the representation of the modern climate in the interior of Greenland and Antarctica is less than perfect for the majority of the PMIP simulations. Temperature errors are rather high for some models, and especially the very low annual precipitation amounts in the Vostok region on the East Antarctic Plateau are poorly simulated by many GCMs. It is known that GCMs, in particular those that do not belong to the latest generation of models, tend to simulate the present-day polar climate poorly [24]. Inadequate atmospheric boundary layer parameterizations [25] or cloud/ radiation schemes [26] are examples of potential sources for errors in polar regions.

We note that annual mean surface temperatures $T_{\mathrm{s}}$ are overestimated in most of the GCM simulations, both for Vostok and Summit (not shown). The deviations between annual mean observations and simulations are substantially larger for Summit than for Vostok. Apparently, surface temperatures at Summit tend to be overestimated by the models because insufficient horizontal model resolution leads to a flattening of the Greenland topography. This is less the case at Vostok because the East Antarctic Plateau is much larger than Greenland. On the other hand, the models repre- sent less accurately the amplitude of the annual temperature cycle at Vostok than at Summit. Therefore, the mean temperature errors $E_{\mathrm{T}}$ at the two sites are of similar magnitude.

We restrict our further analyses to the simulations with a model skill $S>0.6$. This leaves us with a total of 13 models: two versions each of the GENESIS2, LMDZ, ECHAM, UGAMP and UKMO models, plus the UIUC11, CCM3 and YONU GCMs. Three of these models included a slab ocean model, while the others were run with prescribed CLIMAP sea surface temperatures and sea ice conditions [27].

In this context, it is worth noting that the set of models retained is not very sensitive to the applied model skill definition. We tested several alternative definitions of $S_{\mathrm{B}}$ and $S_{\mathrm{T}}$, for example a definition of $S_{\mathrm{B}}$ that took into account simulated and observed seasonal cycles of SMB and a definition of $S_{\mathrm{T}}$ based on annual mean temperatures only. This resulted only in very minor changes in the list of selected models.

\subsubsection{Mass balance seasonality and isotopes}

Table 2 shows the present-day bias $\beta_{0}$ (Eq. 8) for the different models in the Summit and Vostok areas. If the correlations between $T_{\mathrm{B}}$ and $T_{\mathrm{S}}$ were perfect, then $\beta_{0}$ would be zero, as in this case 
$T_{\mathrm{B}}$ would be a perfect proxy of surface air temperature. Indeed $\beta_{0}$ is fairly weak for most of the models. This is consistent with the fact that the correlation coefficient $r^{2}$ for the linear regression between $T_{\mathrm{S}}$ and the SMB-weighted surface air temperature $T_{\mathrm{B}}$ is in general very high (see Table 2 ). The correlations are generally better for Antarctica than for Greenland. In addition, $r^{2}$ tends to be higher for the GCMs with increased spatial resolution. As described in Section 2.2, the bias $\beta_{0}$ over the drill-site area for the present climate can be seen as a measure of significance of potentially large values of $\Delta \beta$ for past climates. The absolute value of $\beta_{0}$ is generally fairly low (below $2^{\circ} \mathrm{C}$ ) for the selected models and higher values of $\left|\beta_{0}\right|$ tend to occur for models with weaker correlations between $T_{\mathrm{S}}$ and $T_{\mathrm{B}}$ only. Thus, possible paleothermometry biases $\Delta \beta$ may be considered meaningful if their absolute value significantly exceeds the simulated mean present-day value of $\beta_{0}$ (about $0 \pm 1^{\circ} \mathrm{C}$ at Vostok and $-1 \pm 1.5^{\circ} \mathrm{C}$ at Summit).

As can be seen in Table 2, the spatial slope $s$ (see Eq. 6) is actually slightly less than 1 for most of the models. Such slopes with $s<1$ can be explained by a linkage between simulated SMB seasonality and annual mean surface air temperature: For the present, the models simulate SMB seasonalities such that at colder locations, the ratio between summer and winter SMB tends to be higher than at warmer places. Therefore, $T_{\mathrm{B}}$ does not decrease as fast as $T_{\mathrm{s}}$ when going from the coast towards the interior of the ice sheets. As a consequence, simulated surface air temperature change $\left|\Delta \tilde{T}_{\mathrm{s}}\right|$ between two different climate periods might be larger than $\left|\Delta T_{\mathrm{B}}\right|$. Even if precipitation reduction in a colder climate takes place essentially in winter, the change of $\Delta \beta$ might be rather small as this summer/winter seasonality relation is already partly included in the present-day relationship between $T_{\mathrm{B}}$ and $T_{\mathrm{s}}$.

\section{2. $L G M$}

\subsubsection{Simulated LGM climate}

The LGM climate differed very strongly from the present one [27]. Representing correctly the full glacial climate is a challenge for any GCM, even for the ones with a good present-day model skill. Therefore, a short assessment of the LGM climate as simulated by the selected models is presented here. LGM simulations were performed for nine out of the 13 selected models.

Recent glaciological evidence [28,29] suggests that the LGM surface topography used in the PMIP simulations [30] is much too high over Central Greenland, the real LGM surface altitude having probably been close to the present-day value, both at Summit and at Vostok. Thus, the simulated LGM surface air temperature has been interpolated from the LGM model surface altitude to present-day altitude, using $\Gamma=\partial T_{\mathrm{s}} / \partial h=$ $10^{\circ} \mathrm{C} / 1000 \mathrm{~m}$. This value, typical for the interior of Greenland and Antarctica [31], is not an atmospheric lapse rate, but the dependency of surface air temperature $T_{\mathrm{s}}$ on surface altitude $h$. The simulated (altitude-corrected) climate change $\Delta_{\mathrm{c}} T_{\mathrm{s}}=\Delta T_{\mathrm{s}}+\Gamma \Delta h$ from the LGM to present (Table 3 ) is generally not as strong as ice core data indicate $[32,33]$. In particular, the large surface cooling over Central Greenland, of the order of $20^{\circ} \mathrm{C}$ $[6,7]$, is reproduced only by the ECHAM GCM. The models with calculated sea surface conditions simulate particularly warm LGM temperatures at Summit. LGM-present-day temperature difference at Vostok is also generally underestimated by the models. It is unclear whether this is a common problem of the models or whether this difference is related to the interpretation of the ice core

Table 3

Observed [32,33] and simulated surface air temperature change $\Delta_{\mathrm{c}} T_{\mathrm{s}}$ (model results corrected for altitude changes) between the LGM and today, for the Vostok and Summit regions

\begin{tabular}{lll}
\hline & \multicolumn{1}{l}{$\Delta_{\mathrm{c}} T_{\mathrm{s}}\left({ }^{\circ} \mathrm{C}\right)$} & \\
\cline { 2 - 3 } & Vostok & Summit \\
\hline Data & $\sim-8$ & $\sim-20$ \\
ECHAM4 fix & -6.9 & -20.5 \\
UKMO cal & -6.0 & -9.4 \\
LMDZ3 fix & -6.7 & -12.9 \\
GENESIS2 cal & -4.2 & -6.8 \\
ECHAM3 fix & -4.5 & -18.0 \\
GENESIS2 fix & -6.8 & -12.2 \\
LMDZ2 fix & -4.6 & -11.5 \\
UGAMP cal & -3.2 & -9.1 \\
UGAMP fix & -4.4 & -10.2 \\
Model mean & $-5.4 \pm 1.3$ & $-12.5 \pm 4.3$ \\
\hline
\end{tabular}


data: The 'observed' $8^{\circ} \mathrm{C}$ temperature difference in Vostok has been obtained using isotopic paleothermometry [32], the validity of which is precisely the object of this study. For the models with fixed sea surface conditions, modeled LGM surface air temperature in Central East Antarctica may suffer from the fact that the CLIMAP dataset [27] has been used to prescribe sea surface conditions, although it has been suggested that the southern hemisphere sea ice extent in this dataset is too large, especially in summer [34,35]. But a reduced, more realistic LGM southern hemisphere sea ice cover would rather increase the Vostok data-model misfit, instead of reducing it.

\subsubsection{Mass balance seasonality and isotopes}

Table 4 displays, for Vostok and Summit at 21 kyr BP, the simulated surface air temperature change $\Delta T_{\mathrm{s}}$ (not corrected for altitude changes), the calculated change of SMB-weighted temperature $\Delta T_{\mathrm{B}}$, and the induced bias $\Delta \beta$ (Eq. 11).

For Antarctica, rather than suggesting a cold isotope paleothermometry bias $\Delta \beta$ which would bring the simulated LGM-present-day temperature difference (see Table 3) into better agreement with isotope-derived LGM surface temperature estimates, the selected models suggest a slight warm bias $\Delta \beta=1.1 \pm 1.1^{\circ} \mathrm{C}$. Taking into account that the scatter of $\beta_{0}$ is about $1{ }^{\circ} \mathrm{C}$, it seems probable that changes in precipitation seasonality in- duce an uncertainty between $0^{\circ} \mathrm{C}$ and $2^{\circ} \mathrm{C}$ in isotope paleothermometry at the LGM at Vostok. Thus, the validity of the isotope paleothermometer is not severely compromised. This is in agreement with previous findings $[15,16,18]$.

For the Greenland Summit region during the LGM, $\Delta \beta$ shows a very large scatter. Values range from $-36^{\circ} \mathrm{C}$ (!) to almost $+7^{\circ} \mathrm{C}$, the mean value being $-4.6 \pm 13.7^{\circ} \mathrm{C}$. The models suggest that a strong bias in isotope paleothermometry is possible, but they deviate even on the sign of this bias. The borehole LGM-present-day temperature difference (about $-20^{\circ} \mathrm{C}$ ) is correctly reproduced by the two versions of the ECHAM GCM only (see Table 3). However, only the newer version ECHAM4 simultaneously suggests a warm seasonality bias of about $+7^{\circ} \mathrm{C}$.

It has been reported that more than half of the PMIP models show a clear seasonality of relative precipitation change in Greenland [36]. The case is not so clear for the models selected here. Four model runs (ECHAM4 fix, UKMO cal, GENESIS2 fix, LMDZ2 fix) do show such a signal in precipitation change; three runs show essentially no signal (LDZZ3 fix, GENESIS2 cal, ECHAM3 fix); and two runs from one model (UGAMP cal and UGAMP fix) simulate a strong precipitation reduction in summer, but not in winter. However, the UGAMP model is an outlier in several respects. First, it is the only model that simulates

Table 4

Simulated LGM-present surface air temperature difference $\Delta T_{\mathrm{S}}$ (not corrected for altitude changes), change in SMB-weighted temperature $\Delta T_{\mathrm{B}}$, and induced isotope paleothermometry bias $\Delta \beta$, for the LGM at Vostok and Summit

\begin{tabular}{lllllll}
\hline & \multicolumn{5}{c}{ Vostok } & \multicolumn{5}{l}{ Summit } \\
\cline { 2 - 7 } & $\begin{array}{l}\Delta T_{\mathrm{s}} \\
\left({ }^{\circ} \mathrm{C}\right)\end{array}$ & $\begin{array}{l}\Delta T_{\mathrm{B}} \\
\left({ }^{\circ} \mathrm{C}\right)\end{array}$ & $\begin{array}{l}\Delta \beta \\
\left({ }^{\circ} \mathrm{C}\right)\end{array}$ & $\begin{array}{l}\Delta T_{\mathrm{s}} \\
\left({ }^{\circ} \mathrm{C}\right)\end{array}$ & $\begin{array}{l}\Delta T_{\mathrm{B}} \\
\left({ }^{\circ} \mathrm{C}\right)\end{array}$ & $\begin{array}{l}\Delta \beta \\
\left({ }^{\circ} \mathrm{C}\right)\end{array}$ \\
\hline ECHAM4 fix & -10.0 & -6.9 & 2.5 & -21.8 & -13.3 & 6.7 \\
UKMO cal & -8.9 & -5.6 & 2.5 & -17.3 & -14.7 & 1.7 \\
LMDZ3 fix & -9.0 & -7.0 & 1.9 & -12.6 & -12.1 & -0.5 \\
GENESIS2 cal & -6.9 & -6.0 & 0.3 & -14.0 & -13.6 & -0.7 \\
ECHAM3 fix & -7.4 & -5.7 & 1.6 & -27.4 & -31.7 & -8.3 \\
GENESIS2 fix & -9.4 & -8.2 & 0.5 & -19.7 & -13.7 & 5.1 \\
LMDZ2 fix & -6.9 & -6.0 & 0.7 & -11.0 & -3.5 & 6.9 \\
UGAMP cal & -6.2 & -6.5 & 0.2 & -18.8 & -26.0 & -25.9 \\
UGAMP fix & -7.3 & -8.9 & -1.1 & -19.9 & -29.5 & -35.8 \\
Model mean & $-8.1 \pm 1.3$ & $-6.7 \pm 1.0$ & $1.1 \pm 1.1$ & $-18.0 \pm 4.7$ & $-17.1 \pm 8.5$ & $-4.6 \pm 13.7$ \\
& & & & $(-17.7 \pm 5.2)$ & $(-14.6 \pm 7.4)$ & $(1.7 \pm 4.8)$ \\
\hline
\end{tabular}

For Summit, Greenland, in parentheses: model mean excluding UGAMP (see text). 
this kind of seasonality of precipitation change (even when taking into account the whole set of PMIP models, no other model is similar to UGAMP in this respect). Second, among the selected models, the UGAMP models are those with the lowest precipitation skill in the Summit region ( 0.62 and 0.64 , while the precipitation skill is usually about 0.8 for the other models). Third, the present-day correlations between $T_{\mathrm{B}}$ and $T_{\mathrm{s}}$ in Greenland are rather low for this model $\left(r^{2}=\right.$ 0.43 and 0.62 , while $r^{2}$ is usually above 0.8 for the other models; see Table 2). Fourth, it has very low spatial slopes $(s=0.53$ and 0.58 , while $s \approx 1$ for the other models; see again Table 2). These low spatial slopes exacerbate the effect of the simulated change in precipitation seasonality on $\tilde{T}_{\mathrm{s}}$, leading to strongly negative values of $\Delta \beta$ for UGAMP. Using long-term meteorological data from coastal stations in Greenland [37] and monthly observed temperature and accumulation values for Summit [22], we can derive a presentday observed spatial slope $s$. This yields $s \approx 1.0$. Although this value is constrained by only one dataset from the interior (i.e. Summit), and must therefore be taken with caution, it is obvious that this observed slope is closer to the values simulated by most of the selected models than to the slopes simulated by UGAMP (see Table 2). For these reasons, the results from UGAMP for Greenland at the LGM must be considered not very trustworthy. Therefore, we also report the
Greenland model mean we obtain when the UGAMP model is excluded (this is also done in the rest of the paper where appropriate). However, even when UGAMP is excluded, $\Delta \beta$ remains rather strongly scattered $\left(\Delta \beta=1.7 \pm 4.8^{\circ} \mathrm{C}\right)$.

\subsection{Mid-Holocene (6 kyr BP)}

\subsubsection{Simulated mid-Holocene climate}

The mid-Holocene climate simulations were run with present-day surface topography. Therefore the simulated surface air temperatures need not be interpolated to present-day altitudes. The modeled surface air temperature change between $6 \mathrm{kyr}$ $\mathrm{BP}$ and present is generally weak. This seems coherent with results from ice core analyses, which indicate only a slight cooling of $-0.7^{\circ} \mathrm{C}$ for Vostok [32] and a warming of $+2^{\circ} \mathrm{C}$ for Summit [33]. Small deviations between modeled and observed temperature changes might be explained by the prescribed present-day sea and land surface conditions for the PMIP 6 kyr BP experiments. Synergistic feedbacks to the atmosphere from ocean and land surface (e.g. vegetation changes), which, at least for the tropics, were shown to to have played a major role reinforcing the orbitally induced climate change between 6 kyr BP and today [38], are not taken into account in the PMIP experiments. For example, a northward shift of the tree line as a response to orbitally induced warmer northern hemisphere climate at $6 \mathrm{kyr}$ BP could

Table 5

Simulated and observed [32,33] mid-Holocene-present surface air temperature difference $\Delta T_{\mathrm{s}}$, change in SMB-weighted temperature $\Delta T_{\mathrm{B}}$, and induced isotope paleothermometry bias $\Delta \beta$, for the mid-Holocene at Vostok and Summit

\begin{tabular}{|c|c|c|c|c|c|c|}
\hline & \multicolumn{3}{|l|}{ Vostok } & \multicolumn{3}{|l|}{ Summit } \\
\hline & $\begin{array}{l}\Delta T_{\mathrm{s}} \\
\left({ }^{\circ} \mathrm{C}\right)\end{array}$ & $\begin{array}{l}\Delta T_{\mathrm{B}} \\
\left({ }^{\circ} \mathrm{C}\right)\end{array}$ & $\begin{array}{l}\Delta \beta \\
\left({ }^{\circ} \mathrm{C}\right)\end{array}$ & $\begin{array}{l}\Delta T_{\mathrm{s}} \\
\left({ }^{\circ} \mathrm{C}\right)\end{array}$ & $\begin{array}{l}\Delta T_{\mathrm{B}} \\
\left({ }^{\circ} \mathrm{C}\right)\end{array}$ & $\begin{array}{l}\Delta \beta \\
\left({ }^{\circ} \mathrm{C}\right)\end{array}$ \\
\hline Data & $\sim-0.7$ & & & $\sim+2$ & & \\
\hline UKMO fix & 0.1 & 1.5 & 1.5 & 0.2 & -0.2 & -0.4 \\
\hline UIUC11 fix & -0.5 & -0.4 & 0.1 & -0.3 & 0.5 & 0.8 \\
\hline ECHAM3 fix & -0.3 & 0.5 & 0.8 & -0.6 & 1.2 & 2.0 \\
\hline GENESIS2 fix & 0.3 & 0.2 & -0.1 & 0.2 & -0.4 & -0.6 \\
\hline CCM3 fix & -0.3 & 0.1 & 0.4 & 0.5 & -0.1 & -0.6 \\
\hline YONU fix & 0.1 & 1.2 & 0.9 & 0.0 & 0.4 & 0.5 \\
\hline UGAMP fix & 0.3 & 0.9 & 0.6 & 0.3 & 1.7 & 3.0 \\
\hline Model mean & $0.0 \pm 0.3$ & $0.6 \pm 0.6$ & $0.6 \pm 0.5$ & $\begin{array}{l}0.0 \pm 0.3 \\
(0.1 \pm 0.4)\end{array}$ & $\begin{array}{l}0.4 \pm 0.7 \\
(0.2 \pm 0.5)\end{array}$ & $\begin{array}{l}0.6 \pm 1.3 \\
(0.3 \pm 0.9)\end{array}$ \\
\hline
\end{tabular}

For Summit, Greenland, in parentheses: model mean excluding UGAMP. 
have further increased this initial warming in the northern high latitudes [39], leading to a stronger warming than simulated by the models.

\subsubsection{Mass balance seasonality and isotopes}

Table 5 also displays $\Delta \beta$ for both drill site areas at $6 \mathrm{kyr}$ BP. For Vostok, $\Delta \beta$ is positive for all models except GENESIS 2 fix, but the fact that the values of $\beta_{0}$ for the present (Table 2) are generally larger than $\Delta \beta$ means that these values are to be considered insignificant. The isotope-derived mid-Holocene temperatures at Vostok are probably not adversely affected by a modified SMB seasonality. For Summit, the probable impact of SMB seasonality changes on isotope paleothermometry $\Delta \beta\left(=0.6 \pm 1.3^{\circ} \mathrm{C}\right)$ is larger than the simulated temperature change $\Delta T_{\mathrm{s}}\left(=0.0 \pm 0.3^{\circ} \mathrm{C}\right)$ itself. However, both values are rather small and deviation among the different models rather high. This prohibits an unequivocal statement about mid-Holocene seasonality changes from these GCM studies.

\section{A note on possible isotope biases at the EPICA and North GRIP sites}

Currently, two new deep ice cores are being drilled within the framework of EPICA (European Project for Ice Coring in Antarctica). The sites are situated in Dronning Maud Laud (DML) at $75^{\circ} \mathrm{S} / 0^{\circ} \mathrm{E}$ and on the Central East Antarctic Plateau at Dome $\mathrm{C}\left(75^{\circ} \mathrm{S}, 123^{\circ} \mathrm{E}\right)$. The results reported above indicate that isotope paleothermometry at Vostok is probably not seriously affected by changes in SMB seasonality, neither for the mid-Holocene nor for the LGM. The question is whether this is also true at the EPICA sites. A short assessment of $\Delta \beta$ in the Dome $\mathrm{C}$ and DML regions is therefore timely. As with the Vostok and Summit sites, $\Delta \beta$ values were calculated for regions centered at the Dome $\mathrm{C}$ and DML sites. The Dome $\mathrm{C}$ area is $30^{\circ}$ wide in longitude and $8^{\circ}$ in latitude (similar to the Vostok area). As the DML site is closer to the coast, the area we regard as representative for the site is smaller $\left(20^{\circ}\right.$ in longitude and $4^{\circ}$ in latitude).

At North GRIP $\left(75^{\circ} \mathrm{N}, 42^{\circ} \mathrm{W}\right)$, about $400 \mathrm{~km}$ NNW of Summit in Central Greenland, another deep core is currently being drilled. North GRIP is actually so close to Summit that it is located within the Summit region as defined in Section 2.2. To be precise, we redefine the North GRIP region as the area between $48^{\circ} \mathrm{W}$ and $36^{\circ} \mathrm{W}$ and between $72^{\circ} \mathrm{N}$ and $78^{\circ} \mathrm{N}$. Our interest focuses on comparing $\Delta \beta$ at the LGM with the values ob-

Table 6

Induced isotope paleothermometry bias $\Delta \beta$ in the DML, Dome C, and North GRIP regions for the mid-Holocene and the LGM

\begin{tabular}{|c|c|c|c|c|c|c|}
\hline & \multicolumn{3}{|c|}{$\begin{array}{l}\Delta \beta, 6 \text { kyr BP } \\
\left({ }^{\circ} \mathrm{C}\right)\end{array}$} & \multicolumn{3}{|c|}{$\begin{array}{l}\Delta \beta, 21 \mathrm{kyr} \mathrm{BP} \\
\left({ }^{\circ} \mathrm{C}\right)\end{array}$} \\
\hline & Dome C & DML & North GRIP & Dome C & DML & North GRIP \\
\hline UKMO fix & -0.5 & 1.9 & -0.1 & & & \\
\hline ECHAM4 fix & & & & 0.8 & -0.8 & 3.5 \\
\hline UKMO cal & & & & 1.5 & 1.9 & 2.2 \\
\hline LMDZ3 fix & & & & 0.7 & 1.3 & -1.0 \\
\hline UIUC11 fix & 3.8 & -0.1 & 1.4 & & & \\
\hline GENESIS2 cal & & & & -0.4 & 0.2 & -1.4 \\
\hline ECHAM3 fix & 0.6 & -1.6 & 1.7 & 0.2 & -0.1 & -8.0 \\
\hline GENESIS2 fix & -0.5 & -0.1 & -1.1 & -0.2 & 0.6 & 2.8 \\
\hline CCM3 fix & 0.8 & 0.8 & 0.2 & & & \\
\hline LMDZ2 fix & & & & 1.7 & 0.4 & 8.8 \\
\hline YONU fix & 3.1 & -0.8 & 0.8 & & & \\
\hline UGAMP cal & & & & -1.3 & -1.0 & -27.2 \\
\hline UGAMP fix & -0.6 & 0.4 & -0.8 & -3.6 & -3.2 & -34.0 \\
\hline Model mean & $0.9 \pm 1.7$ & $0.1 \pm 1.1$ & $\begin{array}{l}0.3 \pm 1.0 \\
(0.5 \pm 0.9)\end{array}$ & $0.1 \pm 1.5$ & $0.0 \pm 1.4$ & $\begin{array}{l}-5.1 \pm 13.2 \\
(1.0 \pm 4.6)\end{array}$ \\
\hline
\end{tabular}

For Greenland, in parentheses: model mean excluding UGAMP. 
tained for Summit, although there are no large differences to expect because of the small distance between the two sites.

Table 6 lists $\Delta \beta$ for the EPICA and North GRIP sites. Mean LGM $\Delta \beta$ is lower at the EPICA sites than at Vostok, while the scatter is similar. Thus the LGM isotope paleothermometer might be slightly more reliable at the EPICA sites than at Vostok, where a small warm bias is suggested by the models. Mid-Holocene scatter of $\Delta \beta$ is larger at the EPICA sites than at Vostok. No firm conclusion about the validity of the isotope paleothermometer for the mid-Holocene can therefore be drawn, but it seems again that the isotope paleothermometer may not be precise enough to yield reliable information on the climate change between the mid-Holocene and today. For North GRIP, the results are similar to those for Summit, and the conclusions reached for Summit can therefore be applied to the North GRIP core: first, there may be major problems with the LGM isotopic record caused by changes in the seasonal precipitation timing and, second, the simulated climate change from the midHolocene to the present is probably smaller than the uncertainties of the isotopic paleothermometry.

\section{Summary, discussion and conclusions}

The results reported above can be summarized as follows:

- Both at Vostok and Summit, the simulated LGM-present temperature change of the majority of the selected GCM simulations is weaker than the ice core analyses indicate.

- Vostok LGM isotope paleothermometry biases $\Delta \beta$, caused by SMB seasonality changes, are fairly small compared to the simulated temperature change but a minor warm bias cannot be excluded.

- Summit LGM $\Delta \beta$ is $1.7 \pm 4.8^{\circ} \mathrm{C}$ (range: $-3^{\circ} \mathrm{C}$ to $+6^{\circ} \mathrm{C}$ ). SMB seasonality changes could explain up to $60 \%$ of the observed isotope paleothermometry bias of about $10^{\circ} \mathrm{C}$, but an opposite effect is suggested by some of the presented model results.
- Vostok mid-Holocene $\Delta \beta$ is small, but positive, indicating that isotopic paleothermometry might slightly overestimate Antarctic temperatures at 6 kyr BP. However, scatter of the present-day $\beta_{0}$ is larger than the mean mid-Holocene $\Delta \beta$, so this result is very uncertain.

- Summit mid-Holocene $\Delta \beta$ is larger than the simulated climate change, but again, it is not significantly larger than the present-day $\beta_{0}$. It seems that isotope paleothermometry is not seriously affected by SMB seasonality changes.

- For the EPICA sites, LGM isotope temperatures might be equal or slightly more accurate than for Vostok. Mid-Holocene scatter of $\Delta \beta$ is higher at the EPICA sites than at Vostok and no firm conclusion about eventual biases of the isotope paleothermometer can therefore be drawn for 6 kyr BP.

- The results for North GRIP are very similar to those for Summit.

This study focussed on possible SMB seasonality changes during past climates. Other local effects that might adversely affect isotope paleothermometry were not addressed. For example, a previous study [15] calculated the precipitationweighted temperature at each model time step, using explicitly the temperature at the atmospheric height where precipitation was formed in the LMDZ GCM. Since the PMIP database only contains monthly data of precipitation, evaporation and surface air temperature, a similar analysis was not possible in this study. Therefore, the role of changes in short-term (sub-monthly) temperatureprecipitation covariance as well as the role of changes in the surface inversion intensity (more exactly, the difference in temperature between the surface and the level where the precipitation forms) could not be examined. The same is true for the impact of changes in the water vapor source regions and transport characteristics between the source regions and the ice sheets, as they can only be examined properly in a full isotopic GCM.

It was shown before [36] that more than half of the PMIP models do show a clear seasonality of relative precipitation change in Greenland. As stated before, the case is not so clear when the 
analysis is restricted to the more skillful models (even after exclusion of the UGAMP model, identified as an outlier). The probability that a change in SMB seasonality caused the warm isotope bias at Summit during the LGM seems somewhat weaker than previously suggested. One reason for this decreased probability is the restricted analysis of the more skillful GCM simulations, e.g. as compared to an analysis of all PMIP models [36]. A second reason is that the present-day spatial slope $s$ (Eq. 6) is lower than unity in most GCM simulations, caused by an increasing modeled ratio of summer vs. winter precipitation from the coast towards the interior of the ice sheets (see Table 2 and discussion in Section 3.1.2). In order to separate this effect of the spatial slope $s$ from the effect of purely local SMB seasonality changes at the drilling sites themselves, $\Delta \beta$ was recalculated for the Summit region at the LGM using the same fixed spatial slope $s=1$ for all models. The inter-model scatter of $\Delta \beta$ calculated in this way is somewhat lower $\left(\Delta \beta=3.1 \pm 4.2^{\circ} \mathrm{C}\right)$ than the scatter obtained when the different modeled slopes $s$ are used $\left(\Delta \beta=1.7 \pm 4.8^{\circ} \mathrm{C}\right)$. That illustrates that SMB seasonality changes alone would tend to induce a warm bias in the LGM isotopic signal at Summit, but the signal is weakened by taking into account the modeled spatial slope $s$. For Vostok, a similar estimate separating the effect of $s$ and SMB seasonality changes is unnecessary, because $\Delta \beta$ is fairly weak for both past periods studied.

The overall conclusion drawn from this study is that temporal isotopic variations in Central Greenland ice cores might show large variations due to changes in SMB seasonality, while East Antarctica ice cores seem less affected. However, neither the sign nor the exact amplitude of the seasonality bias in Greenland can be unmistakably determined by the presented model results. The large differences among the models suggest that the analyses performed in this study may go beyond the limit of present-day modeling capacities. We hope that future-generation climate models will allow us to address unambiguously the question whether ice core isotopic records have been adversely affected by changes in precipitation seasonality.

\section{Acknowledgements}

We are very grateful to the PMIP project members for providing free access to the paleoclimate simulations database (http://www-lsce.cea. fr/pmip/). We used PMIP database release R032001b. This work is a contribution to the European Project for Ice Coring in Antarctica (EPICA), a joint ESF (European Science Foundation)/ EC scientific program, funded by the European Commission and by national contributions from Belgium, Denmark, France, Germany, Italy, The Netherlands, Norway, Sweden, Switzerland and the United Kingdom. This is EPICA publication no. 66. This research was also supported by the French Programme National de l'Etude de la Dynamique du Climat. The ECHAM4 simulations were performed with support from the German Climate Computing Center (DKRZ) in Hamburg, Germany. Data for the Kenton AWS near Summit are available thanks to the Automatic Weather Station Project run by Dr. Charles R. Stearns at the University of Wisconsin-Madison which is funded by the National Science Foundation of the United States of America.[BOYLE]

\section{Appendix}

$E_{\mathrm{T}} \quad$ Annual mean of the absolute monthly surface air temperature bias $\left({ }^{\circ} \mathrm{C}\right)$

$S_{\mathrm{T}} \quad$ Temperature skill

$S_{\mathrm{B}} \quad$ Surface mass balance (SMB) skill

$S \quad$ Combined skill

$T_{\mathrm{s}} \quad$ Surface air temperature $\left({ }^{\circ} \mathrm{C}\right)$

$T_{\mathrm{B}} \quad$ SMB-weighted surface air temperature $\left({ }^{\circ} \mathrm{C}\right)$

$s \quad$ Slope of the regression of $T_{\mathrm{B}}$ against $T_{\mathrm{S}}$ (spatial slope)

$\tilde{T}_{\mathrm{S}} \quad$ Estimated surface air temperature, calculated using $T_{\mathrm{B}}$ $\left({ }^{\circ} \mathrm{C}\right)$

$\beta \quad$ Error of the deduced surface air temperature $\left(=\tilde{T}_{\mathrm{s}}-T_{\mathrm{s}}\right)\left({ }^{\circ} \mathrm{C}\right)$

$\beta_{0} \quad \beta$ for the present $\left({ }^{\circ} \mathrm{C}\right)$

$\Delta \tilde{T}_{\mathrm{s}} \quad$ Estimated surface air temperature change, $\Delta \tilde{T}_{\mathrm{s}}=(1 / s)$ $\Delta T_{\mathrm{B}}\left({ }^{\circ} \mathrm{C}\right)$

$\Delta \beta \quad$ Error of the surface air temperature change deduced from SMB seasonality changes $\left({ }^{\circ} \mathrm{C}\right)$

$\Gamma \quad$ Dependency of surface air temperature on surface altitude $\left({ }^{\circ} \mathrm{C} \mathrm{m}^{-1}\right)$

$\Delta_{\mathrm{c}} T_{\mathrm{s}} \quad$ Simulated surface air temperature change, corrected for altitude changes $\left({ }^{\circ} \mathrm{C}\right)$ 


\section{References}

[1] S. Johnsen, W. Dansgaard, J.W.C. White, The origin of Arctic precipitation under present and glacial conditions, Tellus 41B (1989) 452-468.

[2] C. Lorius, L. Merlivat, Distribution of mean surface stable isotope values in East Antarctica. Observed changes with depth in a coastal area, in: Isotopes and Impurities in Snow and Ice, Vienna, 1977, Proceedings of the Grenoble Symposium Aug./Sep. 1975.

[3] J. Jouzel, R.B. Alley, K.M. Cuffey, W. Dansgaard, P. Grootes, G. Hoffmann, S.J. Johnsen, R.D. Koster, D. Peel, C.A. Shumann, M. Stievenard, J. White, Validity of the temperature reconstruction from water isotopes in ice cores, J. Geophys. Res. 102 (1997) 26471-26488.

[4] J. Jouzel, Towards a calibration of the isotopic paleothermometer, Science 286 (1999) 910-913.

[5] D. Noone, I. Simmons, Associations between $\delta^{18} \mathrm{O}$ of water and climate parameters in a simulation of atmospheric circulation for 1979-95, J. Climate 15 (2002) 3150-3169.

[6] S. Johnsen, D. Dahl-Jensen, W. Dansgaard, N. Gundestrup, Greenland paleotemperatures derived from GRIP bore hole temperature and ice core isotopic profiles, Tellus 47B (1995) 624-629.

[7] K. Cuffey, G.D. Clow, R.B. Alley, M. Stuiver, E. Waddington, R. Saltus, Large Arctic temperature change at the Wisconsin-Holocene deglacial transition, Science 270 (1995) 455-458.

[8] J.P. Severinghaus, E.J. Brook, Abrupt climate change at the end of the last glacial period inferred from trapped air in polar ice, Science 286 (1999) 930-934.

[9] A.N. Salamatin, V.Y. Lipenkov, N.I. Barkov, J. Jouzel, J.-R. Petit, D. Raynaud, Ice core age dating and paleothermometer calibration based on isotope and temperature profiles from deep boreholes at Vostok station (East Antarctica), J. Geophys. Res. 103 (1998) 8963-8977.

[10] V. Rommelaere, Trois problèmes inverses en glaciologie, Doctoral thesis, Université Grenoble 1, Grenoble, 1997.

[11] E.A. Boyle, Cool tropical temperatures shift the global $\delta^{18} \mathrm{O}-\mathrm{T}$ relationship: An explanation for the ice core $\delta^{18}$ O-borehole thermometry conflict?, Geophys. Res. Lett. 24 (1997) 273-276.

[12] F. Loewe, The Greenland ice cap as seen by a meteorologist, Q.J.R. Meteorol. Soc. 62 (1936) 359-377.

[13] D. Noone, J. Turner, R. Mulvaney, Atmospheric signals and characteristics of accumulation in Dronning Maud Land, Antarctica, J. Geophys. Res. 104 (1999) 1919119211.

[14] E.J. Steig, P.M. Grootes, M. Stuiver, Seasonal precipitation timing and ice core records, Science 266 (1995) 18851886.

[15] G. Krinner, C. Genthon, J. Jouzel, GCM analysis of local influences on ice core $\delta$ signals, Geophys. Res. Lett. 24 (1997) 2825-2828.

[16] M. Werner, U. Mikolajewicz, M. Heimann, G. Hoffmann, Borehole versus isotope temperatures on Greenland: Sea- sonality does matter, Geophys. Res. Lett. 27 (2000) 723 726.

[17] M. Werner, M. Heimann, G. Hoffmann, Isotopic composition and origin of polar precipitation in present and glacial climate simulations, Tellus 53B (2001) 53-71.

[18] G. Delaygue, J. Jouzel, V. Masson, R.D. Koster, E. Bard, Validity of the isotopic thermometer in central Antarctica: limited impact of glacial precipitation seasonality and moisture origin, Geophys. Res. Lett. 27 (2000) 2677-2680.

[19] S. Joussaume, K. Taylor, The Paleoclimate Modeling Intercomparison Project, in: P. Braconnot (Ed.), Proceedings of the 3rd PMIP Workshop, No. 111 in WCRP Reports 9-24, WMO, 2000, see also http://www.lsce.cea.fr/ pmip/.

[20] D. Bromwich, Snowfall in high southern latitudes, Rev. Geophys. 26 (1988) 149-168.

[21] C. Genthon, G. Krinner, M. Déqué, Intra-annual variability of Antarctic precipitation from weather forecasts and high resolution climate models, Ann. Glaciol. 27 (1998) 488-494.

[22] C.A. Shuman, R.B. Alley, S. Anandakrishnan, J.W.C. White, P.M. Grootes, C.R. Stearn, Temperature and accumulation at the Greenland Summit: Comparison of high-resolution isotope profiles and satellite passive microwave brightness temperature trends, J. Geophys. Res. 100 (1995) 9165-9177.

[23] I.M. Dolgin, L.S. Petrov, Handbook of Antarctic Climate, Vol. 2, Hydrological Institute, Leningrad, 1977, in Russian.

[24] B. Chen, D.H. Bromwich, K.M. Hines, X. Pan, Simulations of the 1979-1988 polar climates by global climate models, Ann. Glaciol. 21 (1995) 83-90.

[25] G. Krinner, C. Genthon, Z.-X. Li, P. Le Van, Studies of the Antarctic climate with a stretched-grid general circulation model, J. Geophys. Res. 102 (1997) 13731-13745.

[26] J.A. Curry, W.B. Rossow, D. Randall, J. Schramm, Overview of Arctic cloud and radiation characteristics, J. Climate 9 (1996) 1731-1764.

[27] CLIMAP, Seasonal Reconstructions of the Earth's Surface at the Last Glacial Maximum, Geol. Soc. Am. Map Chart Ser. Vol. MC-36, Geol. Soc. Am., 1981.

[28] D. Dahl-Jensen, S.J. Johnsen, C.U. Hammer, H.B. Clausen, J. Jouzel, Past accumulation rates derived from observed annual layers in the GRIP ice core from Summit, Central Greenland, in: W.R. Peltier (Ed.), Ice in the Climate System, NATO ASI Ser. Vol. I 12, Springer, 1993, pp. 517-531.

[29] D. Raynaud, C. Chapellaz, J. Ritz, P. Martinerie, Air content along the GRIP core: a record of surface climatic parameters and elevation in central Greenland, J. Geophys. Res. 102 (1997) 26607-26614.

[30] W.R. Peltier, Ice age paleotopography, Science 265 (1994) 195-201.

[31] G. Krinner, C. Genthon, Altitude dependence of the surface climate over the ice sheets, Geophys. Res. Lett. 26 (1999) 2227-2230. 
[32] J.-R. Petit, J. Jouzel, D. Raynaud, J.M. Barnola, I. Basile, M. Bender, J. Chappellaz, M. Davis, G. Delaygue, M. Delmotte, V.M. Kotlyakov, M. Legrand, V.Y. Lipenkov, C. Lorius, L. Pépin, C. Ritz, E. Saltzman, M. Steivenard, Climate and atmospheric history of the past 420000 years from the Vostok ice core, Antarctica, Nature 399 (1999) $429-436$.

[33] K.M. Cuffey, G.D. Clow, Temperature, accumulation, and ice sheet elevation in central Greenland through the last deglacial transition, J. Geophys. Res. 102 (1997) 26383-26396.

[34] L.H. Burckle, D. Robinson, D. Cooke, Reappraisal of sea-ice distribution in Atlantic and Pacific sectors of the Southern Ocean at 18000 yr BP, Nature 299 (1982) 435437.

[35] X. Crosta, J.J. Pichon, L.H. Burckle, Reappraisal of Antarctic seasonal sea-ice at the Last Glacial Maximum, Geophys. Res. Lett. 25 (1998) 2703-2706.
[36] G. Krinner, D. Raynaud, C. Doutiaux, H. Dang, Simulations of the Last Glacial Maximum ice sheet surface climate: Implications for the interpretation of ice core air content, J. Geophys. Res. 105 (2000) 2059-2070.

[37] P. Frich, H. Alexandersson, J. Ashcroft, B. Dahlström, G.R. Demarée, A. Drebs, A.F.V. van Engelen, E.J. Førland, I. Hanssen-Bauer, R. Heino, T. Jónsson, K. Jonasson, L. Keegan, P. Nordli, T. Schmith, P. Steffensen, H. Tuomenvitra, O.E. Tveito, North Atlantic Climatological Dataset version 1, Scientific Report 96-1, Danish Meteorological Institute, Copenhagen, 1996.

[38] P. Braconnot, S. Joussaume, O. Marti, N. de Noblet, Synergistic feedbacks from ocean and vegetation on the African monsoon response to mid-Holocene insolation, Geophys. Res. Lett. 26 (1999) 2481-2484.

[39] J.A. Foley, J.E. Kutzbach, M.T. Coe, S. Levis, Feedbacks between climate and boreal forests during the Holocene epoch, Nature 371 (1994) 52-54. 